\title{
ANALISIS METODE K-MEANS PADA PENGELOMPOKAN PERGURUAN TINGGI MENURUT PROVINSI BERDASARKAN FASILITAS YANG DIMILIKI DESA
}

\author{
Muhammad Aliyul Amri ${ }^{1}$, Agus Perdana Windarto ${ }^{2}$, Anjar Wanto ${ }^{3}$, Irfan Sudahri Damanik ${ }^{4}$
}

${ }^{1,2,3,4}$ Sistem Informasi, STIKOM Tunas Bangsa, Pematangsiantar, Indonesia

Email: ${ }^{1}$ muhammadaliyul.amri12@gmail.com, ${ }^{2}$ penulis.dua@xmail.ac.id

\begin{abstract}
Abstrak
Perguruan tinggi merupakan jenjang pendidikan yang mencakupprogram diplomat,sarjana dan doctor. Tujuan perguruan tinggi untuk meningkatkan kwalitas tenaga kerja, untuk membantu meningkatkan kwalitas tenaga kerja setiap perguruan tinggi harus memiliki fasilitas- fasilitas yg dibutuhkan dalam kegiatan belajar mengajar. Penelitian ini membahas tentang Analisis Metode KMeans Pada Pengelompokan Perguruan Tinggi Menurut Provinsi Berdasarkan Fasilitas Yang Dimiliki Desa. Sumber data yang diperoleh dari data yang dikumpulkan berdasarkan dokumen-dokumen tahun 2003 sampai tahun 2018 melaui situs Badan Pusat Statistik Indonesia. Data diolah menjadi 2 cluster yaitu cluster tingkat fasilitas tertinggi (C1) dan cluster tingkat fasilitas terendah (C2). Sehingga diperoleh dari 34 provinsi 3 provinsi dikolompokan dalam cluster tingkat fasilitas tinggi (C1) dan 31 provinsi dikelompokkan dalam cluster tingkat fasilitas rendah (C2). Hal ini dapat menjadi masukan pada pemerintah untuk provinsi yang memiliki perguruan tinggi yang masi memiliki fasilitas yg kurang memadai di setiap desa dan menjadi perhatian yang lebih dari pemerintah berdasarkan cluster yang dilakukan.
\end{abstract}

Kata Kunci: K-Means, Perguruan Tinggi, Pengelompokan, fasilitas

\begin{abstract}
Higher education is an education level that includes diplomat, undergraduate and doctoral programs. The purpose of higher education is to improve the quality of the workforce, to help improve the quality of the workforce each university must have the facilities needed in teaching and learning activities. This study discusses the Analysis of the K-Means Method in the Grouping of Universities by Province Based on the Facilities of the Village. Sources of data obtained from data collected based on documents from 2003 to 2018 through the website of the Indonesian Statistics Agency. Data is processed into 2 clusters, namely the highest facility level cluster (C1) and the lowest facility level cluster (C2). So that obtained from 34 provinces 3 provinces are grouped in high facility level clusters $(\mathrm{Cl})$ and 31 provinces are grouped in low facility level clusters (C2). This can be input to the government for provinces that have higher education institutions that still have inadequate facilities in each village and are of more concern to the government based on the cluster that is being conducted.
\end{abstract}

Keywords: K-Means, Higher education, Grouping, Facilities

\section{PENDAHULUAN}

Perguruan tinggi merupakan jenjang pendidikan setelah pendidikan menengah atas atau SMA sederajat, perguruan tinggi mencakup program pendidikan diplomat, sarjana, megister, dan dotor yg diselenggarakan oleh perguruan tinggi. Dengan adanya perguruan tinggi maka semangkin meningkatlah kwalitas tenaga kerja disuatu desa. Dan salah satu cara untuk meningkatkan kwalitas tenaga kerja yaitu melihat fasilitas disebuah perguruan tinggi, karena dengan adanya sarana pendukung terwujudnya proses belajar mengajar yang kondusif diperlukan fasilitas yang memang dibutuhkan didalam seriap perguruan tinggi. Perkembangan Teknologi Informasi dan Komunikasi yang dibantu dengan fasilitas yg baik, memudahkan tenaga pendidik untuk melahir karya-karya yang akan membantu peserta didik dalam pembelajaran, seperti mudahnya belajar secara mandiri melalui jaringan-jaringan Teknologi Informasi dan Komunikasi yang ada, sharing pengetahuan, sharing informasi bahkan dapat dilakukan sharing media pembelajaran seperti modul pembelajaran berbasis multimedia[1].

Banyak cabang ilmu komputer yang dapat menyelesaikan masalah secara kompleks. Mereka diantaranya adalah sistem pendukung keputusan [2]-[6], datamining [7]-[10], sistem pakar [11], jaringan saraf tiruan [12]-[15], algoritma genetika [16] dan lain-lain. Cabang ilmu komputer tersebut adalah Artificial Intelligence seperti datamining[17]. Data mining adalah analisa terhadap data untuk menemukan hubungan yang jelas serta menyimpulkannya yang belum diketahui sebelumnya dengan cara terkini dipahami dan berguna bagi pemilik data tersebut [18]. Clustering akan melakukan pengelompokan data-data ke dalam sejumlah kelompok (cluster) berdasarkan kesamaan karakteristik masing-masing data pada kelompok kelompok yang ada. Banyak metode yang bisa digunakan untuk melakukan clustering salah satunya metode K-Means[19]. K-Means dapat juga diartikan merupakan metode Clustering yang termasuk dalam pendekatan partitioning. Algoritma K-Means merupakan model centroid. Centroid digunakan untuk menghitung jarak suatu objek data terhadap centroid. Suatu objek data termasuk dalam cluster jika memiliki jarak terpendek terhadap centroid cluster tersebut[20]. Tujuan dari K-Means Clustering adalah untuk membagi data kedalam kelompok-kelompok tertentu sehingga menghasilkan pengetahuan baru[21]. Tujuan dari penelitian ini untuk mengelompokkan fasilitas perguruan tinggi yang dimiliki desa dari setiap provinsi di Indonesia. Hal ini perlu dilakukan agar menjadi masukan berupa informasi kepada pemerintah untuk mengetahui desa-desa yang masih memiliki fasilitas perguruan tinggi yang masi belum terpenuhi di suatu provinsi

Algoritma K-Means merupakan algoritma pembelajaran yang sederhana yang dapat menyelesaikan suatu permasalahan untuk meminimalkan kesalahan ganda[22]. Hal ini dibuktikan dalam penelitian terdahulu. Salah satunya dilakuakan oleh Sinta Maulina Dewi[23], dengan kesimpulan bahwa k-means dapat diterapak pada kasus 
pengelompokan Kriminalitas Menurut Wilayah dengan hasil Cluster tinggi (C1) diantaranya Sumatera Utara, Sumatera Selatan, Jawa Barat, Sulawesi Tengah, Sulawesi Selatan, dan Papua. Dan cluster rendah (C2) diantaranya Aceh, Sumatera Barat, Riau, Jambi, Bengkulu, dan 20 provinsi lainnya.

\section{METODOLOGI PENELITIAN}

Dalam penelitian ini menggunakan metode datamining antara lain: a) Tahap pengumpulan data, b) Tahap pengolahan data, c) Tahap clustering dan d) Tahap Analisis.

\subsection{Tahap Pengumpulan Data}

Dalam metode K-Means untuk pengelompokan perguruan tinggi menurut provinsi berdasarkan fasilitas yg dimiliki desa, diperlukan data-data yang akurat dan terkait dengan penelitian ini. Sumber data yang diperoleh dari data yang dikumpulkan berdasarkan dokumen-dokumen tahun 2003 sampai tahun 2018 melaui situs https://www.bps.go.id. Data dikelola dengan melakukan clustering fasilitas perguruan tinggi yang dimiliki desa dalam dua cluster yakni cluster tingkat fasilitas tinggi dan cluster tingkat fasilitas rendah.

\subsection{Tahap Pengelolahan Data}

Data diolah menjadi 2 cluster yaitu cluster tingkat fasilitas tertinggi (C1) dan cluster tingkat fasilitas terendah (C2) sehingga dapat diperoleh perhitunagan nilai yg akan di peroses pada tahap selanjutnya, data setiap wilayah yang memiliki fasilitas perguruan tinggi akan dijumlah setiap aspeknya sehingga pada langkah ini sudah diperoleh data perhitungan nilai yang akan diproses pada prosedur clustering. Proses pengolahan menggunakan bantuan aplikasi RapidMiner.

\subsection{Tahap Clustering}

Clustering merupakan klasifikasi tanpa pengawasan dan merupakan proses partisi sekumpulan objek data dari satu set menjadi beberapa kelas. Hal ini dapat dilakukan dengan menerapkan berbagai persamaan dan langkahlangkah mengenai jarak algoritma, yaitu dengan Euclidean Distance[20].

Dalam menentukan cluster berdasarkan data yang telah tersedia, dibutuhkan sebuah flowchart untuk memudahkan dalam menentukan alur perhitungan sebagai alur untuk menemukan hasil dari penerapan cluster terhadap data yang akan diproses. Berikut adalah flowchart dalam menentukan cluster dengan K-Means[17].

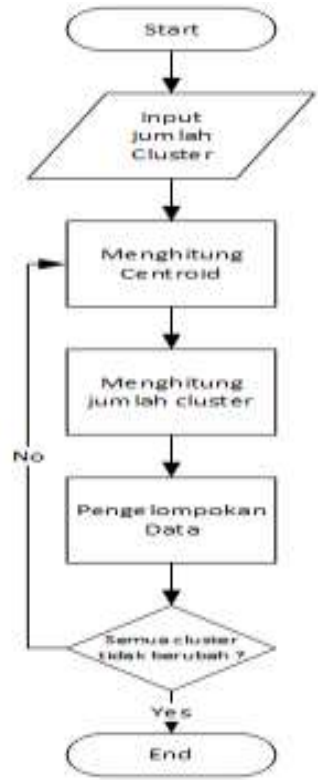

Gambar 1. Flowchart K-Means

\subsection{Tahap Analisis}

Pada tahapan ini dilakukan analisis data ekspor buah buahan menurut negara tujuan aplikasi tool. Rapid Minner. RapidMiner adalah sebuah lingkungan machine learning data mining, text mining dan predictive analytics[20]. Dalam menganalisa pengelompokkan fasilitas prguruan tinggi. Data yang telah diperoleh, kemudian diolah menggunakan perhitungan bobot dari tiap indeks. Pada tahapan sebelumnya, telah ditentukan akan dicluster ke dalam 2 cluster diantaranya cluster rendah dan cluster tinggi, yang hasilnya akan dianilisis.

\section{ANALISA DAN PEMBAHASAN}


Dalam melakukan clustering, data yang telah diperoleh akan dihitung berdasarkan jumlah data fasilitas perguruan tinggi yang dimiliki desa pada tahun 2003-2018 menurut provinsi. Berikut data fasilitas perguruan tinggi yang dimiliki desa pada tahun 2003-2018:

Tabel 1. Rancangan Analisis Komputasi

\begin{tabular}{|c|c|c|c|c|c|c|}
\hline \multirow{2}{*}{ Provinsi } & \multicolumn{6}{|c|}{ Perguruan Tinggi } \\
\hline & 2003 & 2005 & 2008 & 2011 & 2014 & 2018 \\
\hline Aceh & 54 & 67 & 77 & 120 & 118 & 115 \\
\hline Sumatera Utara & 115 & 125 & 168 & 181 & 177 & 193 \\
\hline Sumatera Barat & 60 & 79 & 90 & 113 & 98 & 116 \\
\hline Riau & 36 & 60 & 60 & 63 & 65 & 79 \\
\hline Jambi & 0 & 35 & 48 & 33 & 45 & 50 \\
\hline Sumatera Selatan & 43 & 54 & 73 & 84 & 81 & 90 \\
\hline Bengkulu & 21 & 14 & 26 & 24 & 29 & 30 \\
\hline Lampung & 39 & 44 & 76 & 60 & 71 & 70 \\
\hline Kep. Bangka Belitung & 8 & 7 & 11 & 14 & 16 & 16 \\
\hline Kep. Riau & 23 & 0 & 20 & 20 & 32 & 32 \\
\hline DKI Jakarta & 104 & 122 & 120 & 137 & 146 & 139 \\
\hline Jawa Barat & 207 & 277 & 359 & 351 & 411 & 394 \\
\hline Jawa Tengah & 163 & 181 & 210 & 228 & 235 & 252 \\
\hline DI Yokyakarta & 54 & 52 & 59 & 56 & 59 & 58 \\
\hline Jawa Timur & 246 & 260 & 322 & 353 & 381 & 376 \\
\hline Banten & 48 & 73 & 123 & 118 & 126 & 123 \\
\hline Bali & 32 & 34 & 47 & 42 & 44 & 43 \\
\hline Nusa Tenggara Barat & 31 & 41 & 73 & 65 & 73 & 72 \\
\hline Nusa Tenggara Timur & 23 & 36 & 47 & 55 & 58 & 62 \\
\hline Kalimantan Barat & 22 & 30 & 45 & 47 & 50 & 54 \\
\hline Kalimantan Tengah & 16 & 16 & 15 & 15 & 21 & 17 \\
\hline Kalimantan Selatan & 32 & 34 & 51 & 52 & 47 & 57 \\
\hline Kalimantan Timur & 37 & 41 & 54 & 49 & 46 & 47 \\
\hline Kalimantan Utara & 0 & 0 & 0 & 0 & 9 & 12 \\
\hline Sulawesi Utara & 36 & 41 & 47 & 58 & 62 & 58 \\
\hline Sulawesi Tengah & 33 & 50 & 41 & 31 & 36 & 38 \\
\hline Sulawesi Selatan & 90 & 126 & 150 & 164 & 148 & 165 \\
\hline Sulawesi Tenggara & 26 & 27 & 37 & 67 & 40 & 35 \\
\hline Gorontalo & 6 & 16 & 15 & 15 & 11 & 15 \\
\hline Sulawesi Barat & 0 & 0 & 21 & 20 & 23 & 22 \\
\hline Maluku & 16 & 17 & 26 & 34 & 40 & 44 \\
\hline Maluku Utara & 9 & 11 & 21 & 17 & 20 & 24 \\
\hline Papua Barat & 0 & 0 & 25 & 24 & 29 & 36 \\
\hline Papua & 37 & 48 & 39 & 41 & 54 & 54 \\
\hline
\end{tabular}

\subsection{Centroid Data}

Dalam penerapan algoritma K-means dihasilkan nilaicentroid dari data yang didapat dengan ketentuan klasterisasi yang diinginkan adalah 2[22]. Penentuan cluster dibagi atas 2 cluster yaitu cluster tingkat fasilitas tinggi (C1), dan cluster tingkat fasilitas rendah (C2).

Tabel 2. Centroid awal

\begin{tabular}{lcccccc}
\hline Cluster tinggi & 246 & 277 & 359 & 353 & 411 & 394 \\
\hline Cluster rendah & 6 & 7 & 11 & 14 & 9 & 12 \\
\hline
\end{tabular}

\subsection{Clustering Data}

Dengan didapatkan centroid awal maka cluster data yang telah didapat menjadi 2 cluster. Proses cluster dilakukan dengan mengambil jarak terdekat dari setiap data yang diolah.

Tabel 3. Penentuan jarak pusat Cluster iterasi 1

\begin{tabular}{lcccc}
\hline \multicolumn{1}{c}{ Provinsi } & Cluster 1 & Cluster 2 & Jarak Terdekat & Cluster \\
\hline Aceh & 548,0392 & 182,9754 & 182,9754 & $\mathrm{C} 2$ \\
Sumatera Utara & 401,1047 & 326,7231 & 326,7231 & $\mathrm{C} 2$ \\
Sumatera Barat & 549,0464 & 179,3516 & 179,3516 & $\mathrm{C} 2$ \\
Riau & 619,7508 & 108,2312 & 108,2312 & $\mathrm{C} 2$ \\
Jambi & 672,1704 & 62,32175 & 62,32175 & $\mathrm{C} 2$ \\
Sumatera Selatan & 594,7193 & 132,6047 & 132,6047 & $\mathrm{C} 2$ \\
Bengkulu & 696,0488 & 31,89044 & 31,89044 & $\mathrm{C} 2$ \\
\hline
\end{tabular}




\begin{tabular}{lcccc}
\hline \multicolumn{1}{c}{ Provinsi } & Cluster 1 & Cluster 2 & Jarak Terdekat & Cluster \\
\hline Lampung & 615,1032 & 112,6987 & 112,6987 & $\mathrm{C} 2$ \\
Kep. Bangka Belitung & 721,9529 & 7,549834 & 7,549834 & $\mathrm{C} 2$ \\
Kep. Riau & 703,951 & 31,68596 & 31,68596 & $\mathrm{C} 2$ \\
DKI Jakarta & 466,8362 & 262,1736 & 262,1736 & $\mathrm{C} 2$ \\
Jawa Barat & 39,05125 & 714,1148 & 39,05125 & $\mathrm{C} 1$ \\
Jawa Tengah & 291,1443 & 437,7648 & 291,1443 & $\mathrm{C} 1$ \\
DI Yokyakarta & 623,9119 & 104,6088 & 104,6088 & $\mathrm{C} 2$ \\
Jawa Timur & 50,39841 & 687,0218 & 50,39841 & $\mathrm{C} 1$ \\
Banten & 522,2021 & 208,0385 & 208,0385 & $\mathrm{C} 2$ \\
Bali & 658,2158 & 68,85492 & 68,85492 & $\mathrm{C} 2$ \\
Nusa Tenggara Barat & 616,9141 & 111,2744 & 111,2744 & $\mathrm{C} 2$ \\
Nusa Tenggara Timur & 646,7109 & 80,98148 & 80,98148 & $\mathrm{C} 2$ \\
Kalimantan Barat & 658,3297 & 68,942 & 68,942 & $\mathrm{C} 2$ \\
Kalimantan Tengah & 710,8614 & 18,62794 & 18,62794 & $\mathrm{C} 2$ \\
Kalimantan Selatan & 649,9762 & 77,05842 & 77,05842 & $\mathrm{C} 2$ \\
Kalimantan Timur & 646,2941 & 81,20961 & 81,20961 & $\mathrm{C} 2$ \\
Kalimantan Utara & 742,9381 & 20,04994 & 20,04994 & $\mathrm{C} 2$ \\
Sulawesi Utara & 636,8909 & 90,23857 & 90,23857 & $\mathrm{C} 2$ \\
Sulawesi Tengah & 664,812 & 67,24582 & 67,24582 & $\mathrm{C} 2$ \\
Sulawesi Selatan & 442,1301 & 287,249 & 287,249 & $\mathrm{C} 2$ \\
Sulawesi Tenggara & 658,5302 & 72,58788 & 72,58788 & $\mathrm{C} 2$ \\
Gorontalo & 719,668 & 10,24695 & 10,24695 & $\mathrm{C} 2$ \\
Sulawesi Barat & 715,926 & 20,66398 & 20,66398 & $\mathrm{C} 2$ \\
Maluku & 685,887 & 42,63801 & 42,63801 & $\mathrm{C} 2$ \\
Maluku Utara & 711,7415 & 16,34013 & 16,34013 & $\mathrm{C} 2$ \\
Papua Barat & 708,9485 & 28,37252 & 28,37252 & $\mathrm{C} 2$ \\
Papua & 650,3653 & 78,87966 & 78,87966 & $\mathrm{C} 2$ \\
\hline
\end{tabular}

Grafik Clustering Interasi 1

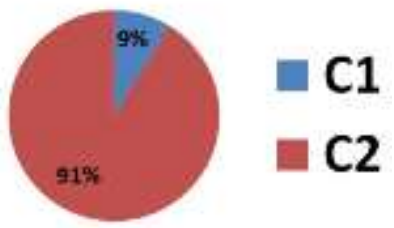

Gambar 2. Grafik Clustering Interasi 1

Proses akan terus melakukan iterasi sampai data pada iterasi terakhir sama dengan iterasi sebelumnya[1]. .Proses iterasi tersebut berhenti pada iterasi ke 2, pada iterasi ini akan dilakukan pencarian nilai titik tengah atau centroid pada table berikut :

Tabel 4. Centroid Intterasi 4

\begin{tabular}{lcccccc}
\hline Cluster tinggi & 205,3333 & 239,3333 & 297 & 310,6667 & 342,3 & 340,7 \\
\hline Cluster rendah & 35,45161 & 44,29032 & 58,96774 & 62,48387 & 64,52 & 67,39 \\
\hline
\end{tabular}

Setelah mendapatkan nilai centroid, proses yang sama dilakukan dengan mencari jarak terdekat.

Tabel 5. Penentuan jarak pusat Cluster iterasi 1

\begin{tabular}{lcccc}
\hline \multicolumn{1}{c}{ Provinsi } & Cluster 1 & Cluster 2 & Jarak Terdekat & Cluster \\
\hline Aceh & 432,9597 & 86,03009 & 86,03009 & C2 \\
Sumatera Utara & 286,1365 & 227,0558 & 227,0558 & C2 \\
Sumatera Barat & 433,8476 & 80,57325 & 80,57325 & C2 \\
Riau & 504,9694 & 16,133 & 16,133 & C2 \\
Jambi & 557,7904 & 51,92503 & 51,92503 & C2 \\
Sumatera Selatan & 479,8945 & 33,24808 & 33,24808 & C2 \\
Bengkulu & 581,5839 & 70,13017 & 70,13017 & C2 \\
Lampung & 500,8471 & 18,80416 & 18,80416 & C2 \\
Kep. Bangka Belitung & 607,3674 & 95,38436 & 95,38436 & C2 \\
Kep. Riau & 589,6949 & 80,38626 & 80,38626 & C2 \\
DKI Jakarta & 351,9514 & 163,4824 & 163,4824 & C2 \\
Jawa Barat & 107,9851 & 614,1834 & 107,9851 & C1 \\
Jawa Tengah & 176,1518 & 338,2511 & 176,1518 & C1 \\
DI Yokyakarta & 509,4014 & 21,60009 & 21,60009 & C2
\end{tabular}




\begin{tabular}{lcccc} 
Jawa Timur & 77,64306 & 587,2968 & 77,64306 & C1 \\
Banten & 407,9209 & 109,5434 & 109,5434 & C2 \\
Bali & 543,6848 & 32,81988 & 32,81988 & C2 \\
Nusa Tenggara Barat & 502,5218 & 17,62008 & 17,62008 & C2 \\
Nusa Tenggara Timur & 531,9982 & 21,44948 & 21,44948 & C2 \\
Kalimantan Barat & 543,7166 & 31,89574 & 31,89574 & C2 \\
Kalimantan Tengah & 596,3213 & 84,91086 & 84,91086 & C2 \\
Kalimantan Selatan & 535,3212 & 24,24105 & 24,24105 & C2 \\
Kalimantan Timur & 531,7052 & 23,28469 & 23,28469 & C2 \\
Kalimantan Utara & 628,4484 & 116,7327 & 116,7327 & C2 \\
Sulawesi Utara & 522,1632 & 13,09209 & 13,09209 & C2 \\
Sulawesi Tengah & 550,3024 & 46,22193 & 46,22193 & C2 \\
Sulawesi Selatan & 326,8885 & 187,9137 & 187,9137 & C2 \\
Sulawesi Tenggara & 543,4327 & 38,20888 & 38,20888 & C2 \\
Gorontalo & 604,988 & 93,09785 & 93,09785 & C2 \\
Sulawesi Barat & 601,4652 & 90,23902 & 90,23902 & C2 \\
Maluku & 571,291 & 59,99153 & 59,99153 & C2 \\
Maluku Utara & 597,2279 & 85,18547 & 85,18547 & C2 \\
Papua Barat & 594,5394 & 84,16219 & 84,16219 & C2 \\
Papua & 535,7967 & 31,20302 & 31,20302 & C2 \\
\hline
\end{tabular}

Grafik Clustering Interasi 2

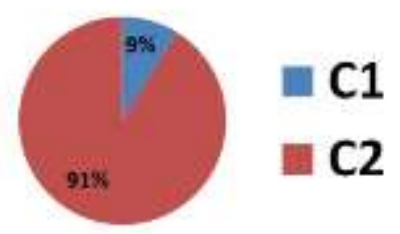

Gambar 3. Grafik Clustering Interasi 2

\subsection{Analisis Data}

Pada iterasi 2, pengelompokan data yang dilakukan terhadap 2 cluster didapatkan hasil yang sama dengan iterasi 1. Dari 34 provinsi di indonesia dapat dikertahui, 3 provinsi cluster fasilitas tinggi (C1) yaitu Jawa Barat, Jawa Tengah dan Jawa Timur, dan 31 provinsi lainnya dengan cluster fasilitas rendah (C2).

\section{KESIMPULAN}

Untuk melakukan penilaian terhadap hasil pengelompokan perguruan tinggi menurut fasilitas yang dimiliki desa dapat menerapkan metode clustering K-Means. Data diolah untuk memperoleh nilai dari fasilitas perguruan tinggi. Data tersebut diolah menggunakan Rapidminner untuk ditentukan nilai centroid dalam 2 cluster yaitu cluster tingkat fasilitas tingkat dan cluster tingkat fasilitas rendah. Dimana hasil penelitian menyimpulkan dari 34 provinsi di indonesian dan 2 cluster yang ada diperoleh 3 provinsi dengan cluster tinggi (C1) yaitu Jawa Barat, Jawa Tengah dan Jawa Timur. Dan 31 provinsi lainnya dengan cluster rendah (C2).

\section{REFERENCES}

[1] K. Fanny Irnanda, "Penerapan K-Means pada Proporsi Individu dengan Keterampilan (Teknologi Informasi dan Komunikasi) TIK Menurut Wilayah,” Semin. Nas. Sains Teknol. Inf., pp. 452-456, Jul. 2019.

[2] S. M. Dewi and A. P. Windarto, "Analisis Metode Electre Pada Pemilihan Usaha Kecil Home Industry Yang Tepat Bagi Mahasiswa," Sist. J. Sist. Inf., vol. 8, no. 3, pp. 377-385, 2019.

[3] D. R. S. P, A. A. Muin, and M. Amin, "PEMILIHAN FACIAL WASH UNTUK KULIT WAJAH BERMINYAK DENGAN METODE PROMETHEE II,” CESS (Journal Comput. Eng. Syst. Sci., vol. 4, no. 2, pp. 222-229, 2019.

[4] C. Astria, A. P. Windarto, and Z. Musiafa, "PEMILIHAN PRODUK SAMPO SESUAI JENIS KULIT KEPALA DENGAN METODE PROMETHEE II,” CESS (Journal Comput. Eng. Syst. Sci., vol. 4, no. 2, pp. 178-185, 2019.

[5] D. N. Batubara, A. P. Windarto, and M. R. Raharjo, "PENERAPAN PROMETHEE II PADA PEMILIHAN PRODUK CONDITIONER SEBAGAI UPAYA PENINGKATAN MINAT BELI KONSUMEN," CESS (Journal Comput. Eng. Syst. Sci., vol. 4, no. 2, pp. 191-197, 2019.

[6] D. N. Batubara, D. R. S. P, and A. P. Windarto, "Penerapan Metode PROMETHEE II Pada Pemilihan Situs Travel Berdasarkan Konsumen," J. SISFOKOM, vol. 8, no. 1, pp. 46-52, 2019.

[7] A. P. Windarto, "Penerapan Datamining Pada Ekspor Buah-Buahan Menurut Negara Tujuan Menggunakan K-Means Clustering Method," Techno.Com, vol. 16, no. 4, pp. 348-357, 2017.

[8] M. G. Sadewo et al., "PENERAPAN ALGORITMA CLUSTERING DALAM MENGELOMPOKKAN BANYAKNYA DESA / KELURAHAN MENURUT UPAYA ANTISIPASI / MITIGASI BENCANA ALAM MENURUT PROVINSI 
DENGAN K-MEANS,” vol. 2, pp. 311-319, 2018.

[9] H. Siahaan, H. Mawengkang, S. Efendi, A. Wanto, and A. P. Windarto, "Application of Classification Method C4 . 5 on Selection of Exemplary Teachers," in IOP Conference Series, 2018, pp. 1-6.

[10] Sudirman, A. P. Windarto, and A. Wanto, "Data mining tools | rapidminer: K-means method on clustering of rice crops by province as efforts to stabilize food crops in Indonesia," IOP Conf. Ser. Mater. Sci. Eng., vol. 420, p. 12089, 2018.

[11] S. Azhar, H. Latipa, S. Leni, and N. Zulita, "Sistem Pakar Penyakit Ginjal Pada Manusia Menggunakan Metode Forward Chaining," J. Media Infotama, vol. 10, no. 1, pp. 16-26, 2014.

[12] T. Budiharjo, Soemartono, T., Windarto, A.P., Herawan, "Predicting tuition fee payment problem using backpropagation neural network model," Int. J. Adv. Sci. Technol., 2018.

[13] T. Budiharjo, Soemartono, T., Windarto, A.P., Herawan, "Predicting school participation in indonesia using back-propagation algorithm model," Int. J. Control Autom., 2018.

[14] A. P. Windarto, M. R. Lubis, and Solikhun, "MODEL ARSITEKTUR NEURAL NETWORK DENGAN BACKPROPOGATION PADA PREDIKSI TOTAL LABA RUGI KOMPREHENSIF BANK UMUM KONVENSIONAL," Kumpul. J. Ilmu Komput., vol. 5, no. 2, pp. 147-158, 2018.

[15] A. P. Windarto, M. R. Lubis, and Solikhun, "IMPLEMENTASI JST PADA PREDIKSI TOTAL LABA RUGI KOMPREHENSIF BANK UMUM KONVENSIONAL DENGAN BACKPROPAGATION,” J. Teknol. Inf. dan Ilmu Komput., vol. 5, no. 4, pp. 411-418, 2018.

[16] Sumijan, A. P. Windarto, A. Muhammad, and Budiharjo, "Implementation of Neural Networks in Predicting the Understanding Level of Students Subject," Int. J. Softw. Eng. Its Appl., vol. 10, no. 10, pp. 189-204, 2016.

[17] C. Astria, "Metode K-Means Pada Pengelompokan Wilayah Pendistribusian Listrik," Semin. Nas. Sains Teknol. Inf., pp. 306 -312 , Jul. 2019.

[18] B. Melpa Metisen, "ANALISIS CLUSTERING MENGGUNAKAN METODE K-MEANS DALAM PENGELOMPOKKAN PENJUALAN PRODUK PADA SWALAYAN FADHILA,” J. Media Infotama, vol. 11, no. 2, pp. 110-118, Sep. 2015.

[19] L. Maulida, "PENERAPAN DATAMINING DALAM MENGELOMPOKKAN KUNJUNGAN WISATAWAN KE OBJEK WISATA UNGGULAN DI PROV. DKI JAKARTA DENGAN K-MEANS,” JISKa (Jurnal Inform. Sunan Kalijaga), vol. 2, no. 3, pp. 167-174, Jan. 2018.

[20] A. P. Windarto, "Penerapan Data Mining Pada Ekspor Buah-Buahan Menurut Negara Tujuan Menggunakan K-Means Clustering," Techno.COM, vol. 16, no. 4, pp. 348-357, 2017.

[21] M. Anjelita, "Analisis Metode K-Means pada Kasus Ekspor Barang Perhiasan dan Barang Berharga Berdasarkan Negara Tujuan,” Semin. Nas. Sains Teknol. Inf., pp. 476 - 482, Jul. 2019.

[22] D. Nabila Batubara, "Analisis Metode K-MEANS Pada Pengelompokan Keberadaan Area Resapan Air Menurut Provinsi," Semin. Nas. Sains Teknol. Inf., pp. 345 - 349, Jul. 2019.

[23] S. Maulina Dewi, “Analisa Metode K-Means pada Pengelompokan Kriminalitas Menurut Wilayah,”Semin. Nas. Sains Teknol. Inf., pp. 620 - 625, Jul. 2019. 